\title{
Modelling Phosphorus Losses from Tropical Agricultural Soils in Gilgel Gibe Watershed, Ethiopia
}

\section{Yalemsew Adela ${ }^{1 *}$ and Christian Behn ${ }^{2}$}

${ }^{1}$ Jimma University, Institute of Technology, School of Civil and Environmental Engineering, Ethiopia

${ }^{2}$ Rostock University, Faculty of Agricultural and Environmental Sciences, Resources Management and Soil Physics, Rostock, Germany

\begin{abstract}
Phosphorus $(P)$ is a vital nutrient for plants, however its excess loss from agricultural lands cause eutrophication on aquatic environment. The Gilgel gibe reservoir located in the southwest part of Ethiopia is exposed to this phenomenon whereby the water quality has been classified as mesotrophic with $\mathrm{P}$ concentration of $0.86 \mathrm{mg} / \mathrm{l}$. The objectives of this study were to identify the operating $\mathrm{P}$ loss mechanisms from agricultural lands, quantify the amount of $\mathrm{P}$ exported and evaluate the factors for $\mathrm{P}$ loss using the best management practices (BMPs) concepts. Therefore, experimental data and the annual phosphorus loss estimation (APLE) model were used to study the underlying processes. Catenas surrounding the reservoir, used as arable and pastureland, were investigated. Topsoil samples were taken and analyzed at three slope positions. The soils are mainly nitisol and a smaller portion of vertisol where the parent materials are basalt and rhyolite. The APLE model was set using soil data from the arable lands with nitisol soil and hydrologic records. The phosphorus loss was simulated from 2001 to 2010 . Besides, the experimental $\mathrm{P}$ sorption data were used to check the logical consistency of the model output. On average $12.66 \pm 0.7 \mathrm{~kg} \mathrm{P} \mathrm{ha}^{-1}$ $\mathrm{yr}^{-1}$ is lost in the form of particulate and total dissolved P. Generally, $56 \%$ of $\mathrm{P}$ is lost in the form of particulate $\mathrm{P}$ due to erosion, and $44 \%$ as soils dissolved and direct fertilizer runoff $P$. A significant variation observed between the sediment and soil dissolved $P$ loss $(p$-value $=0.000)$ which is attributed to the soil chemical and physical properties that control the phosphorus dynamics. Obviously the dominant $P$ transfer from agricultural lands into the Gilgel Gibe River and reservoir is particulate $\mathrm{P}$ loss. An evaluation of causing factors using BMPs indicated that a reduction of sediment by $5-20 \%$ resulted to retain $\mathrm{P}$ from $2-9 \%$. Similarly, a reduction of soil $\mathrm{P}$ content reduces the $\mathrm{P}$ loss from $2-8.5 \%$. However, a reduction of fertilizer quantity applied on the fields within the same percent range is hardly reducing $\mathrm{P}$ loss relative to the earlier factors. Therefore, attention should be given to the application of precision agriculture to avoid such problems.
\end{abstract}

Keywords: Particulate loss, P loss, P sorption, Soil dissolved P, Tropical soil

\section{Introduction}

Phosphorus $(\mathrm{P})$ is a limiting nutrient in the aquatic environment where its excess presence impairs water quality significantly by accelerating the growth of algae and aquatic plants causing eutrophication $[1,2]$. Previously the impact of phosphorus to cause a problem as a non-point source pollutant was underestimated in comparison with nitrogen due to its hardly mobility in the agricultural landscape. Currently there is a consensus that phosphorus is a major non-point source pollutant that causes eutrophication in surface waters. The intrinsic property that affects the mobility of phosphorus is its sorption affinity for soil particles. However, in the presence of high soil and stream bank erosion, an increased amount of phosphorus is transported in surface water. Additionally, the contribution of dissolved phosphorus is also more significant than previously thought [3].The Gilgel gibe catchment can be referred as agricultural catchment due to the intensive agricultural practice carried out. Despite the catchment comprise a very sensitive development infrastructure, there had not been a mechanism to evaluate and manage the problem associated with nutrient transport and loading. The impact of phosphorus in this catchment has also been continuing on the reservoir water quality. Scientifically researched and published information on the overall aquatic environment of the reservoir is hardly found. The Gilgel gibe reservoir had high turbidity and elevated phosphate concentrations of $0.3-0.7 \mathrm{mg} / \mathrm{L}$, which is much higher than the permissible limit of $0.025 \mathrm{mg} / \mathrm{L}$ for lakes and reservoir [4]. To address the problem of phosphorus, the transport process needs critical attention. Several fields and laboratory techniques developed to understand the movement of phosphorus and its fate. Besides this, transport and loading models are available that are taking special attention recently. To understand the problem in this catchment, appropriate model development or utilization would help a lot. Models developed to evaluate P loss under various conservation practices give emphasis both on steady state and dynamic process, which attributes complexity of the model features [5]. Most commonly, US Environmental Protection Authority uses Spreadsheet Tool for the Estimation of Pollutant Load (STEPL) and $\mathrm{P}$ load tools to evaluate conservation practices [1]. Beyond these, simple field-scale models, phosphorus indices are used for conservation planning and regulation under the application of animal manure in the US and Europe [6]. A phosphorus index is typically a tool that yields a categorical rating of phosphorus loss from a single field. These indices are valuable tools to assess the potential risk of phosphorus leaving a site and travelling toward a water body, but they were not initially developed to be quantitative predictors of phosphorus loss [1,7]. A tool that reliably quantifies field-scale phosphorus loss is an alternative to qualitative $\mathrm{P}$ Indexes and process- based models and remains easy

*Corresponding author: Yalemsew Adela, Jimma University, Institute of Technology, School of Civil and Environmental engineering, Ethiopia, Tel: +251911974550; E-mail: yalemsew.adela@ju.edu.et

Received June 22, 2015; Accepted July 25, 2015; Published July 30, 2015

Citation: Adela Y, Behn C (2015) Modelling Phosphorus Losses from Tropical Agricultural Soils in Gilgel Gibe Watershed, Ethiopia. Hydrol Current Res 6: 214 doi:10.4172/2157-7587.1000214

Copyright: ( 2015 Adela Y, et al. This is an open-access article distributed under the terms of the Creative Commons Attribution License, which permits unrestricted use, distribution, and reproduction in any medium, provided the original author and source are credited. 
to use with its feature that requires only readily obtainable inputs. A field-scale P loss quantification tool offers attractive characteristics for $\mathrm{P}$ loss reduction planning. This is due to the ease in designing realistic assumptions for the relative effect of different management practices on $\mathrm{P}$ loss and validation with measured data, which eventually give a clear picture of $\mathrm{P}$ loss forms [6]. Though process based models like the Soil and Water Assessment Tool (SWAT) can be used to identify management strategies and gives larger picture at the watershed scale for water quality assessment, the requirement of large data makes it difficult for immediate consumption [8]. In addition, watershed-scale predictions of $\mathrm{P}$ loadings to fresh water bodies are not reliable unless extensive, site-specific calibration is used. In Gilgel gibe watershed there are no gauging stations for in-stream phosphorus concentration and so many other soil data which are required to assess the transport of $\mathrm{P}$ from land into water bodies. Therefore, it is better to use the field scale phosphorus model which gives a clear picture to visualize the other part of the catchment heuristically. Annual Phosphorus Loss Estimator (APLE) as a field-scale P loss quantification tool possesses a remarkable feature. The soil $\mathrm{P}$ algorithms developed make the model applicable for a wide variety of soil types, climates, and management conditions [8]. Therefore, the objectives of this study were to identify the dominant $\mathrm{P}$ losses mechanism, quantify the amount of $\mathrm{P}$ loss from agricultural fields and evaluate the factors for P loss using BMPs concept.

\section{Methods and Materials}

\section{Description of the catchment}

Gilgel gibe catchment is located in the south-western part of Ethiopia in Jimma zone, Oromia region situated within Omo-Gibe basin. The whole Gilgel gibe sub catchment which sheds water to the reservoir lies between latitude of $7^{\circ} 21^{\prime}$ to $7^{\circ} 58^{\prime} \mathrm{N}$ and longitude of $3631^{\prime}$ to $37^{\circ} 26^{\prime} \mathrm{E}$ covering an area of about $4300 \mathrm{~km}^{2}$. The area is flat plateau about 1,650 $\mathrm{m}$ a.s.l and consists of a series of gentle sloping low hills and broad plains surrounded by hills or mountains. The Gilgel gibe River, which flows from southwest to northeast, is a tributary of the Great Gibe River and is extremely variable in the course and gradient. The Gilgel gibe is the main river, which creates the reservoir that covers an area of $55 \mathrm{~km}^{2}$. The annual rainfall of the catchments area varies from a minimum of 1,300 mm near the confluence with the Great Gibe River, to a maximum of about $1,800 \mathrm{~mm}$ on the mountains. Rainfall decreases throughout the catchments with a decrease in elevation. The average annual rainfall over the whole Gilgel gibe basin where it joins the Great Gibe River is $1,527 \mathrm{~mm}$. It appears that 60 per cent of the total amount of annual rainfall occurs between June and September 30 per cent from February to May and only 10 per cent between Octobers to January [9]. The gentle slopes and the central plains of the foothills of the ridge is intensely cultivated and densely populated area. The agricultural sector uses various type of fertilizers (i.e. superphosphate $\left(\mathrm{P}_{2} \mathrm{O}_{5}\right)$, Diammonum phosphate (DAP) and Urea) to enhance the productivity. However, the management of these agricultural inputs is traditional and unsupported with soil fertility test examination before application.

\section{Description of the arable lands investigated for model set up}

Soil property: The red balloon on figure 1(a) and (b) represents the six catenas where soil samples were taken around the reservoir. Six catenas surrounding the reservoir (120 to $440 \mathrm{~m} \mathrm{long}$ ), used as arable and pastureland, extended on the flatter edge of the catchment were investigated. Topsoil samples were taken at three slope positions. Catena 5 and 6 are uniquely vertisol at each slope position, however, the other four catenas possess a nitisol soil at least at one position along the catena. Therefore, as it is also reported in several literatures, nitisol soils are common for this watershed. Consequently, this study focused on the $\mathrm{P}$ loss from the fields which are nitisol by type. For P loss estimation the land which grows teff is considered for both types of the soils. The $\mathrm{P}$ loss from the vertisol lands was used for comparative reasoning and to check the consistency of the model. Detailed laboratory analysis was

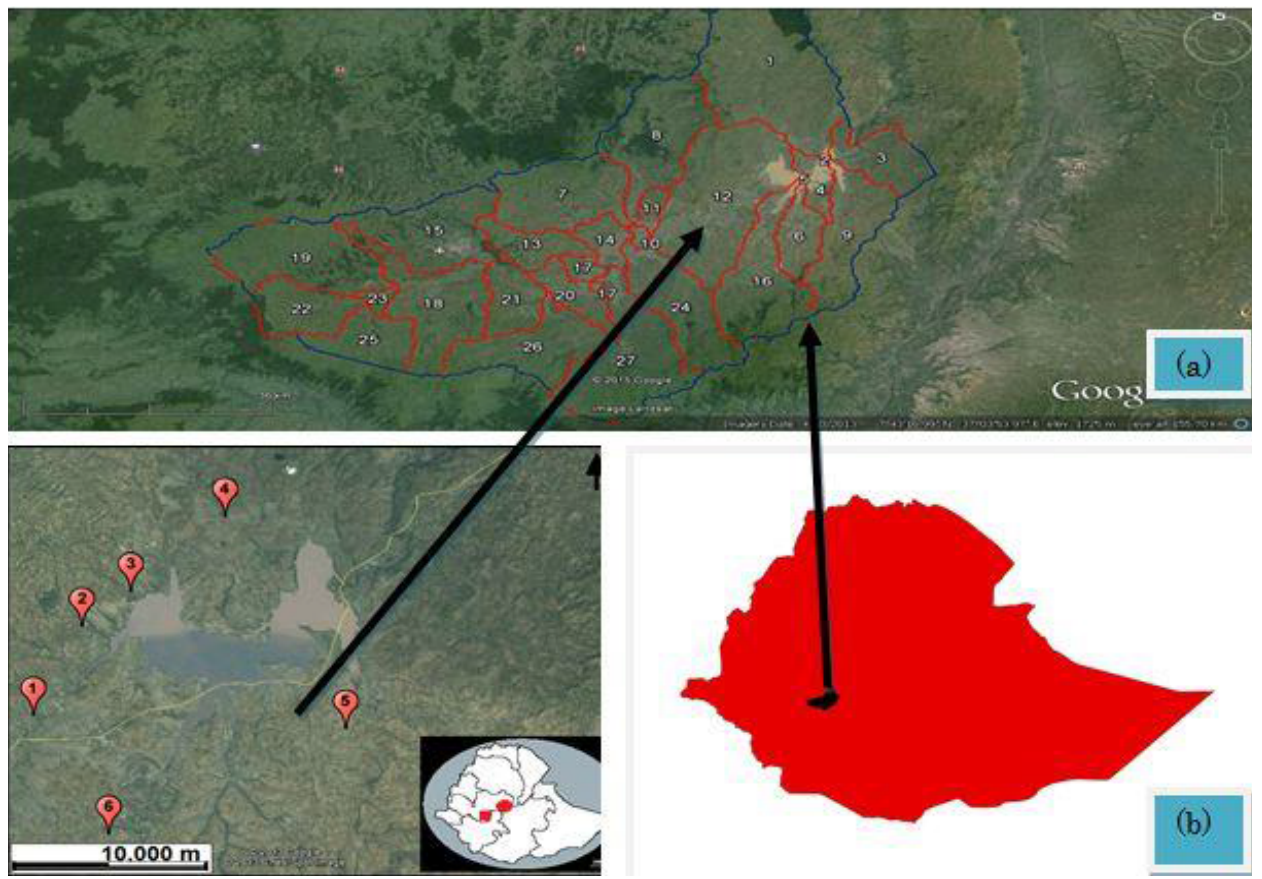

Figure 1: (a) Delineated KML map of Gilgel Gibe catchment and (b) Location of catenas around the Gilgel Gibe reservoir and location of Gilgel Gibe catchment in Ethiopia. 
Citation: Adela Y, Behn C (2015) Modelling Phosphorus Losses from Tropical Agricultural Soils in Gilgel Gibe Watershed, Ethiopia. Hydrol Current Res 6: 214. doi:10.4172/2157-7587.1000214

Page 3 of 8

\begin{tabular}{|c|c|c|c|c|c|}
\hline Catena & Slope & Soil & Landuse & Spot & Texture \\
\hline \multirow[t]{3}{*}{1} & 7.6 & Vertisol & Fallow & 1 & Silty clay loam \\
\hline & & & & 2 & Clay \\
\hline & & & & 3 & Clay \\
\hline \multirow[t]{3}{*}{2} & 2.6 & Nitisol & Grazing & 1 & Clay \\
\hline & & & & 2 & Clay \\
\hline & & & & 3 & Clay \\
\hline \multirow[t]{3}{*}{3} & 8.2 & Nitisol & Deforested & 1 & Clay \\
\hline & & & & 2 & Clay \\
\hline & & & & 3 & Clay \\
\hline \multirow[t]{3}{*}{4} & 4 & Nitisol & Teff & 1 & Clay \\
\hline & & & & 2 & Clay \\
\hline & & & & 3 & Clay \\
\hline \multirow[t]{3}{*}{5} & 4.6 & Vertisol & Grazing & 1 & Clay \\
\hline & & & & 2 & Clay \\
\hline & & & & 3 & Clay \\
\hline \multirow[t]{3}{*}{6} & 2.3 & Vertisol & Teff & 1 & Clay \\
\hline & & & & 2 & Clay \\
\hline & & & & 3 & Clay \\
\hline
\end{tabular}

Table 1: Soil properties for each catena.

\begin{tabular}{|c|c|c|c|c|c|c|c|c|c|c|c|}
\hline Soil type & Soil test P $(\mathrm{ppm})$ & Soil clay \% & $\begin{array}{c}\text { SHC, ks, } \\
\mathrm{cm} / \mathrm{day}\end{array}$ & Soil OM \% & Al(g/kg) & Fe(g/kg) & C \% & N \% & BS (\%) & $\begin{array}{c}\text { Unstable } \\
\text { aggregates (\%) }\end{array}$ & Fertilizer applied kg/ha/yr \\
\hline Nitisol & 510 & 70 & 19.2 & 2.8 & 64.8 & 88.5 & 2.6 & 0.25 & 96.1 & 23.2 \\
\hline Vertisol & 290 & 54 & 36.7 & 2.2 & 42.4 & 54.3 & 2.1 & 0.19 & 99.2 & 41.3 \\
\hline
\end{tabular}

Table 2: General characteristics of the arable lands (BS: Base Saturation, OM: Organic Matter, SHC: Saturated Hydraulic Conductivity).

\begin{tabular}{|c|c|c|c|c|c|c|c|c|c|}
\hline \multicolumn{5}{|c|}{ Freundlich Isotherm parameters } & \multicolumn{5}{|c|}{ Langmuir Isotherm parameters } \\
\hline Soil Type & $P\left(\mathbf{m g ~ k g}^{-1}\right)$ & k & $1 / n$ & $r^{2}$ & Soil Type & $P\left(\mathrm{mg} \mathrm{kg}^{-1}\right)$ & b & k & $\mathbf{r}^{2}$ \\
\hline Nitisol & 469 & 943 & 0.17 & 0.94 & Nitisol & 469 & 2931 & 0.08 & 0.92 \\
\hline Vertisol & 273 & 513 & 0.18 & 0.95 & Vertisol & 273 & 1629 & 0.07 & 0.9 \\
\hline
\end{tabular}

Table 3: P-sorption data as explained by Freundlich and Langmuir sorption isotherms.

carried out for several variables where the model requires. Standard laboratory methods were employed for all experiments. A summary of the soil characteristics and other relevant information about the fields are indicated in table 1and 2. To run the model, an average crop P uptake of $7.6 \mathrm{~kg} / \mathrm{ha}$ was considered based on literatures. Even though pastureland is available in this catena, only croplands were considered for simulating the $\mathrm{P}$ loss due to the assumption that the inorganic fertilizer from the croplands causes the problem. However, pasturelands with higher cattle density could contribute a considerable amount of phosphorus from dung. In this catchment, cattle dung is used for energy purpose by the residents so that picking the dung from the field is common.

Soil Phosphorus sorption: Batch experiments were conducted with $7 \mathrm{P}$ concentrations ranging from 0 to $500 \mathrm{mg} / \mathrm{l}$, and the adsorption isotherms were evaluated using Freundlich and Langmuir models. As it is shown in table 3 and figure 2, P sorption fit to both the Freundlich and Langmuir isotherms. The result is indicative that the data best fit to the Freundlich isotherm (Vertisol, $\mathrm{r}^{2}=0.95$ and Nitisol, $\mathrm{r}^{2}=0.94$ ) though the Langmuir isotherm also explained the process very well (Vertisol, $\mathrm{r}^{2}=0.9$ and Nitisol, $\mathrm{r}^{2}=0.92$ ).

The sorption maximum of nitisol soil was significantly higher than the vertisol. This implied that $\mathrm{P}$ sorbed into the two soils also varies by which the higher sorption tendency of $\mathrm{P}$ to nitisol soils observed. This phenomenon was associated to soil chemical characteristics (clay content, $\mathrm{Al}$ and Fe concentrations). Accordingly, results and discussion plausibly conclude that nitisol soils had shown a higher tendency to fix P. Similar results are also found for such a soil type [10,11 and 12].

Annual rainfall and runoff: While studying the transfer of phosphorus from soils into the nearby aquatic environment, it is very important to have rainfall-runoff data which determines the major P loss dynamics. Figure 3 shows the average annual rainfall-runoff data used in this study. Gilgel gibe is well known for receiving higher precipitation relative to other part of the country. The dominant clay texture of the area, gentle steepness, and lower land cover cause a moderate to higher runoff annually causing large amount of soil erosion.

The runoff coefficient is determined using curve number method based on the lands feature which is approximated 0.25 . The annual runoff then calculated using the simple method where it is calculated as a product of annual runoff volume, and a runoff coefficient (Rv). Runoff volume is calculated as:

$$
\mathrm{R}=\mathrm{P}^{*} \mathrm{Pj}^{*} \mathrm{Rv}
$$

Equation 1

Where: $\mathrm{R}=$ Annual runoff $(\mathrm{mm}), \mathrm{P}=$ Annual rainfall $(\mathrm{mm}), \mathrm{Pj}=$ Fraction of annual rainfall events that produce runoff (usually 0.9 ), $\mathrm{Rv}$ $=$ Runoff coefficient.

\section{APLE Model and Modelling Approach}

Model Description: The APLE model is an empirical model, with process-based equations based only on experimental data and not spatially explicit model that runs on an annual time step. The model simulates sediment bound and dissolved $\mathrm{P}$ loss in surface runoff. It 

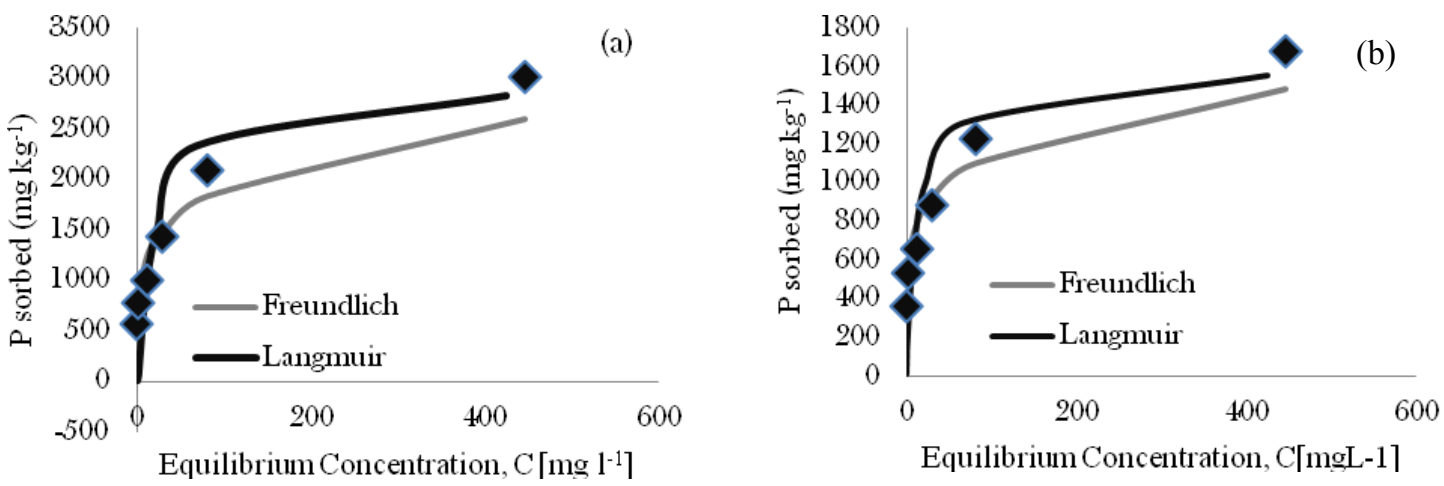

Figure 2: Sorption isotherms for (a) nitisol and (b) vertisol soils.

does not consider subsurface loss of $\mathrm{P}$ through leaching to groundwater or artificial drainage networks. It simulates edge-of-field P loss for uniform fields of several hectares in size, or smaller. APLE does not simulate P loss through grassed waterways or buffers that may occur beyond the field edge. The model considers different kinds of animal manure, applied either by machine or by grazing beef or dairy cattle, but considers only highly soluble commercial fertilizers such as superphosphate, triple superphosphate, or mono- and di-ammonium phosphate. APLE model calculates annual total surface P loss from agricultural fields as:

$\mathrm{P}_{\text {tot }}=\mathrm{DP}_{\text {man }}+\mathrm{DP}_{\text {fert }}+\mathrm{DP}_{\text {soil }}+\mathrm{P}_{\text {sed }}$ Equation 2

Where $\mathrm{P}_{\text {tot }}$ is the total annual $\mathrm{P}$ loss from surface runoff $\left(\mathrm{kg} \mathrm{ha}^{-1}\right)$,

$\mathrm{DP}_{\text {man }}$ is annual dissolved $\mathrm{P}$ loss in runoff from applied manure $(\mathrm{kg}$ $\left.\mathrm{ha}^{-1}\right)$, $\mathrm{ha}^{-1}$,

$\mathrm{DP}_{\text {fert }}$ is annual dissolved P loss in runoff from applied fertilizer ( $\mathrm{kg}$

$\mathrm{DP}_{\text {soil }}$ is annual dissolved $\mathrm{P}$ loss in runoff from soil $\left(\mathrm{kg} \mathrm{ha}^{-1}\right)$, and

$\mathrm{P}_{\text {sed }}$ is annual sediment $\mathrm{P}$ loss from eroded soil $\left(\mathrm{kg} \mathrm{ha}^{-1}\right)$.

The model gives a detailed information about fertilizer dissolved $\mathrm{P}$ loss in runoff, sediment bound and dissolved phosphorus runoff from soil, soil phosphorus processes, soil Mixing between topsoil layers and phosphorus leaching from topsoil layers. APLE mixes P between the two topsoil layers based on the user-defined degree of soil mixing based on tillage or natural mixing processes, such as mixing by earthworms or freeze-thaw actions. It also estimates a concentration of dissolved $\mathrm{P}(\mathrm{mg}$ $\left.\mathrm{L}^{-1}\right)$ in the soil leachate based on a phosphorus sorption isotherm, which relates the amount of $\mathrm{P}$ sorbed on the soil and the amount dissolved in the soil water. A detail of the model can be obtained from the APLE theoretical documentation [13].

APLE model set up: APLE requires soil, rainfall, runoff, erosion, and fertilizer application, soil mixing method and depth and annual crop $\mathrm{P}$ uptake data. Soil data include the soil test $\mathrm{P}$, clay content, organic matter and depth of the top two soil layers. In order to set up the model, the data were obtained from regional agricultural offices, farmers' interview, field measurements, Ethiopian Institute of Agricultural Research (Jimma Branch). Soil properties (chemical and physical) and soil test $\mathrm{P}$ were obtained from laboratory analysis. Rainfall data were collected from the nearby Asendabo and Jimma metrology stations. Sediment data were obtained from Vlamse Interuniversiteit Raad-Flemish Inter University Cooperation (VLIR-IUC) projects soil degradability study team. The model was set for the period of 10 years from 2001 to 2010 on arable land. It is assumed that P due to manure application was set to nil because of no application of manure. Moreover, the role of cattle dung during grazing is also negligible due to the collection practice ( researcher observation) for energy purpose by the residents and weak practice of composting the farmlands. Therefore, the outputs of this study fundamentally consider the phosphorus from inorganic fertilizers and soils. Because of the nature of the model, calibration is not required. However validating the model output is essential and P sorption data were used to check whether the model output is realistic or not. This was done by comparing the P lost from two different lands with different soil, i.e. nitisol and vertisol. The limitation of this study design could be associated with the data quality for runoff and sediment. This is due to the assumption made for runoff computation and the sediment data assumed to be similar with the actual field data which was obtained from the nearby fields. The simulated model output data analyses were dispatched using Minitab version 16.00 statistical packages. Descriptive and non-parametric inferential (Mann-Whitney Test, ANOVA, Correlation) statistics were done for different variables. In order to show the presence of water quality problem due to $\mathrm{P}$, random water samples were collected by grab sampling technique from the river and reservoir to evaluate the concentration of Orthophosphates phosphorus, the analyses were done in the laboratory according to standard methods.

\section{Results and Discussion}

\section{Water quality}

The fate of most diffuse source pollutants in agricultural catchment is the aquatic environment found in proximity. Particularly in agricultural catchments, the main nutrients that diffuse are nitrogen and phosphorus. In this catchment the intensive agricultural practice with the presence of the rugged topography, makes the movement of nutrients facilitated. In addition to these, there is no strategy to test the nutrient status of the soil before applying fertilizers. These and others made the situation very serious and attention seeking. As shown in table 4, the average concentration of phosphate is thirty-four times greater than the permissible value of $0.025 \mathrm{mg} / \mathrm{L}$ for lakes and reservoir [14]. This finding confirms that the reservoir is highly influenced by the intrusion of phosphorus from diffuse sources that cause severe water quality and aquatic ecosystem perturbations. Similarly Gilgel gibe reservoir exhibited higher likelihood of having a rapid nutrient enrichment [15]. Vividly all these facts are indicative of the presence of phosphorus enrichment. The following results and discussion below are taking this finding as a footstep to understand the transport phenomena 
of phosphorus in this catchment.

\section{Phosphorus loss}

Total P loss: Phosphorus loss from agricultural lands is commonly controlled by the hydrologic events, such as surface runoff. The runoff can transport $\mathrm{P}$ as sediment bound (particulate) or dissolved form. In this study, an average of $12.66 \pm 0.7 \mathrm{~kg} \mathrm{ha}^{-1} \mathrm{yr}^{-1}$ phosphorus is lost from the nitisol dominated lands. This value was based on yearly soil erosion rate of $2.75 \mathrm{tha}^{-1}$ and runoff coefficient of 0.25 independent of soil type. The total P loss is the sum of the sediment bound, soil dissolved and fertilizer runoff loss. A field scale quantitative nutrient flow analysis reported that 7-11 $\mathrm{kg} \mathrm{ha}^{-1} \mathrm{yr}^{-1}$ of $\mathrm{P}$ is lost from cropland at the lowlands of this catchment where exactly the investigated fields for this study are found [16]. This showed that the finding of this study has shown a strong agreement with the reported one. Positive correlation was found between runoff and total $\mathrm{P}$ loss $\left(\mathrm{r}^{2}=0.89\right.$, $\mathrm{p}$-value $\left.=0.001\right)$. These variables are also correlated positively and strongly in other catchments [17].

Particulate P loss: Phosphorus is well understood to its affinity to bind with the soil that affects its movement on surface and subsurface water. Lands with a higher concentration of aluminum and iron oxides, potentially bind $\mathrm{P}$ where its movement depends on this property. From this study field, particulate $P$ contributes the largest portion $(7.1 \pm 0.3$ $\mathrm{kg} \mathrm{ha}^{-1}$ ) of its total loss. Analysis of variance within the nitisol group revealed that significant variation observed between the sediment and soil dissolved $\mathrm{P}$ loss $(\mathrm{p}$-value $=0.000)$ which is attributed to the soil chemical and physical properties that control the phosphorus dynamics. The higher clay content, aluminum and iron oxide in nitisol soils favor high adsorption of $\mathrm{P}(\mathrm{p}$-value $=0.001)[10-12,18]$. Consequently, the prevailing hydrological events, such as runoff and erosion transport $\mathrm{P}$ at large. Henceforth, the high P sorption affinity to soil in the presence of surface runoff would result in a magnificent sediment $\mathrm{P}$ loss.

Total dissolved P loss: The total dissolved $\mathrm{P}$ (soil dissolved and fertilizer runoff $\mathrm{P})$ loss $\left(4.5 \pm 0.6 \mathrm{~kg} \mathrm{ha}^{-1}\right)$ was also found as considerable amount on the overall phosphorus loss. It was found strongly correlated with run off $\left(r^{2}=0.91, p\right.$-value $\left.=0.000\right)$ which is also discussed in other literatures $[17,19]$. In conclusion, this study found that the major phosphorus loss mechanism was particulate $\mathrm{P}(56 \%)$. The remaining fraction of $\mathrm{P}$ transported as soil dissolved $\mathrm{P}$ and direct fertilizer runoff ( $36 \%$ of $\mathrm{P}$ is lost as soil dissolved $\mathrm{P}$ and $8 \%$ as fertilizer runoff). Research output indicate that that up to $86 \%$ of the total P load per annum is contributed in the form of sediment bound $\mathrm{P}$, which supports the present finding in this catchment [20].

P pools: While understanding all the facts and operating processes on the P loss at agricultural fields, it is important to identify the pools whereby $\mathrm{P}$ is stored. Therefore, major phosphorus pools that contribute to the studied transport dynamics, the model had simulated the three inorganic $\mathrm{P}$ pools (Labile, Active, and Stable) and one Organic $\mathrm{P}$ pool.

Looking into figure 4 the largest portion of $\mathrm{P}$ lost through erosion is contributed from the soil stable $\mathrm{P}$ pools due to the sorption process taking place in this pool; followed by active and labile $\mathrm{P}$ pools. On the contrary, the lowest contributor is the organic $\mathrm{P}$ pool where this tendency is related to the lower soil organic matter. This implies that the high iron and aluminum oxides in the soil mainly affected the $\mathrm{P}$ behavior where sorption occurs. Consequently the prevailing erosion would transport $\mathrm{P}$ mainly for the overall transfer from lands into rivers.

\section{Model sensitivity and Uncertainty analysis}

This section examines the effect of model input variables in APLE model and identifies the degree of sensitivity observed and uncertainties associated with the model predictors. Sensitivity and uncertainty analysis done for APLE model using First Order Approximation (FOA) and Monte Carol Simulation (MCS) showed that the MCS was found better for its overall uncertainty analysis [21]. Therefore, in this study the MCS technique was employed after reducing the $\mathrm{DP}_{\text {man }}$ component of equation 2 due to the absence of manure application on the study area. There are nine parameters which affect P loss in APLE model. A sensitivity analysis was done on five model predictors, which are significantly determining the $\mathrm{P}$ loss in this catchment. Consequently, the sediment, runoff coefficient, runoff, labile $\mathrm{P}$ and fertilizer applied parameters were found to be the most sensitive parameters. The input parameter values were obtained from independent measurements and records. To make the simulated output credible and the model prediction valid, the uncertainty analyses were performed using Monte Carlo simulation with an adequate number of simulations (i.e. 200000) by assuming a triangular distribution of uncertainty which gives better distribution of data sets [21]. The model prediction uncertainties were calculated using the same input data sets as of sensitivity analysis (Table 5). As it is shown in table 6, high uncertainty value is associated with annual runoff, erosion and runoff coefficient parameters. Relatively lower uncertainties can occur due to the remaining parameters. Uncertainties in measured $\mathrm{P}$ loss data are a function of errors introduced when measuring runoff, erosion, and concentration of $\mathrm{P}$ in solution and attached to sediment [21]. After Monte Carlo simulation, the predicted value of P loss to 95\% CI $[10.59,10.94]$ was $10.77 \pm$ $0.17 \mathrm{~kg} \mathrm{ha}^{-1}$. Comparing with the initial APLE model output for total P loss value $\left(12.67 \pm 0.7 \mathrm{~kg} \mathrm{ha}^{-1}\right)$, and nearly $1.9 \pm 1 \mathrm{~kg} \mathrm{ha}^{-1}$ variation was observed. This implied that there is a comparable result between the initial simulated P loss and P loss after MCS. Though uncertainty analysis was incorporated, the incorporation of uncertainties with $\mathrm{P}$ model predictions is still not standard practice [5]. Even though these arguments have been in place, in this study the need for uncertainty analysis will play a great role to make the output result credible and robust model prediction.

\section{Comparison of $\mathbf{P}$ loss from nitisol and vertisol soils}

The comparison of $\mathrm{P}$ loss from these two different soils aspires to check the logical consistency of the model output to that of the experienced fact. The logic behind this argument was that, these two soils have different clay and mineralogical content so that their phosphorus sorption capacity would also be different. This prompts to examine different response from the two soils after running the model. Since APLE simulate P loss in the form of sediment and dissolution via runoff, the $\mathrm{P}$ sorbed to soils would prefer the sediment transport and the dissolved $\mathrm{P}$ follow the dissolved transport mechanism. A statistical analysis showed that on average $12.66 \pm 0.7 \mathrm{~kg} \mathrm{ha}^{-1} \mathrm{yr}^{-1}$

\begin{tabular}{|c|c|c|c|c|}
\hline Parameters & Mean & St Dev & Min & Max \\
\hline Temperature & 21.3 & 2.08 & 19 & 23 \\
\hline $\mathrm{pH}$ & 7.33 & 0.25 & 7.1 & 7.6 \\
\hline Turbidity(FTU) & 100 & 11.14 & 90 & 112 \\
\hline Conductivity( $\mu \mathrm{S} / \mathrm{cm})$ & 92.67 & 7.64 & 86 & 101 \\
\hline $\mathrm{DO}(\mathrm{mg} / \mathrm{L})$ & 6.03 & 0.68 & 5.5 & 6.8 \\
\hline $\mathrm{BOD}(\mathrm{mg} / \mathrm{L})$ & 2.47 & 0.4 & 2.1 & 2.9 \\
\hline Nitrate(mg N/L) & 1.66 & 0.99 & 0.62 & 2.6 \\
\hline Phosphate(mg P/L) & 0.86 & 0.32 & 0.5 & 1.1 \\
\hline
\end{tabular}

Table 4: Water quality status of the Gilgel Gibe reservoir for three different seasons in 2013 and in river $P$ concentration (Min: Minimum, Max: Maximum, BOD $:$ 5-day Biological Oxygen Demand, DO: Dissolved Oxygen). 


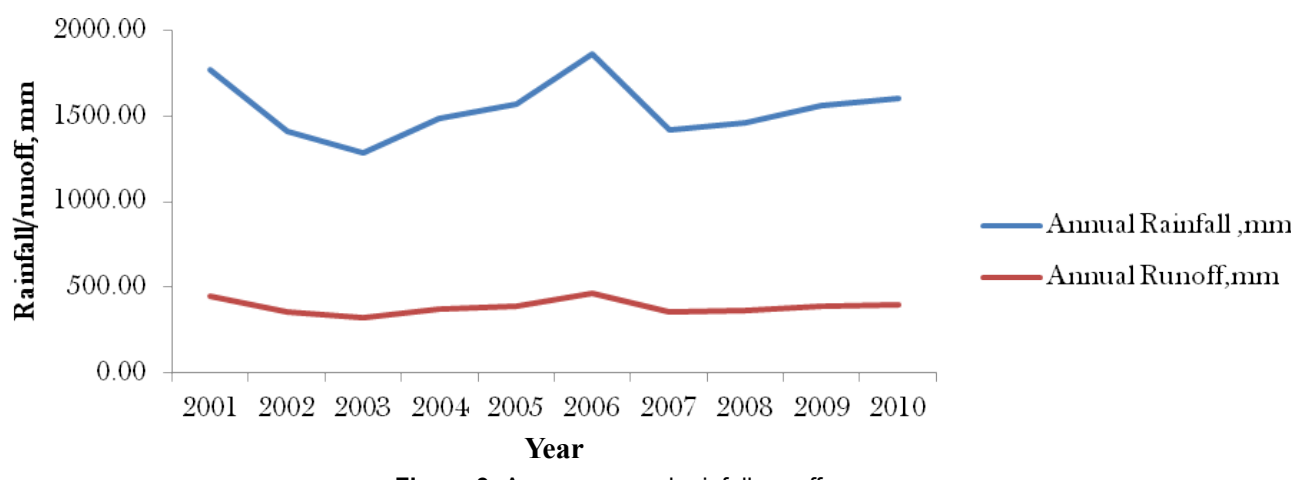

Figure 3: Average annual rainfall-runoff curve

\begin{tabular}{|c|c|c|c|c|}
\hline Sensitivity Rank & Model Variable & Input value & Variable range & Lower and Upper boundary \\
\hline 1 & SED, $\mathrm{kg} \mathrm{ha}^{-1}$ & 2790.4 & 0.47 to $1.34 \times 10^{5}$ & \pm 15 \\
\hline 2 & RO/PT\% & 25 & Dec-40 & \pm 25 \\
\hline 3 & $\mathrm{RO}, \mathrm{mm}$ & 385.8 & $0-720$ & \pm 25 \\
\hline 4 & $\mathrm{LP}, \mathrm{mg} \mathrm{kg}^{-1}$ & 173.4 & $5.5-500$ & \pm 15 \\
\hline 5 & FERT $_{\text {TP }}$ & 80.75 & $0-150$ & \pm 15 \\
\hline
\end{tabular}

FERT $_{\text {TP }}$-total phosphorus applied, LP-labile phosphorus, RO annual runoff, RO/PT- runoff/precipitation; SED- erosion.

Table 5: Input data set, variable range and boundaries.

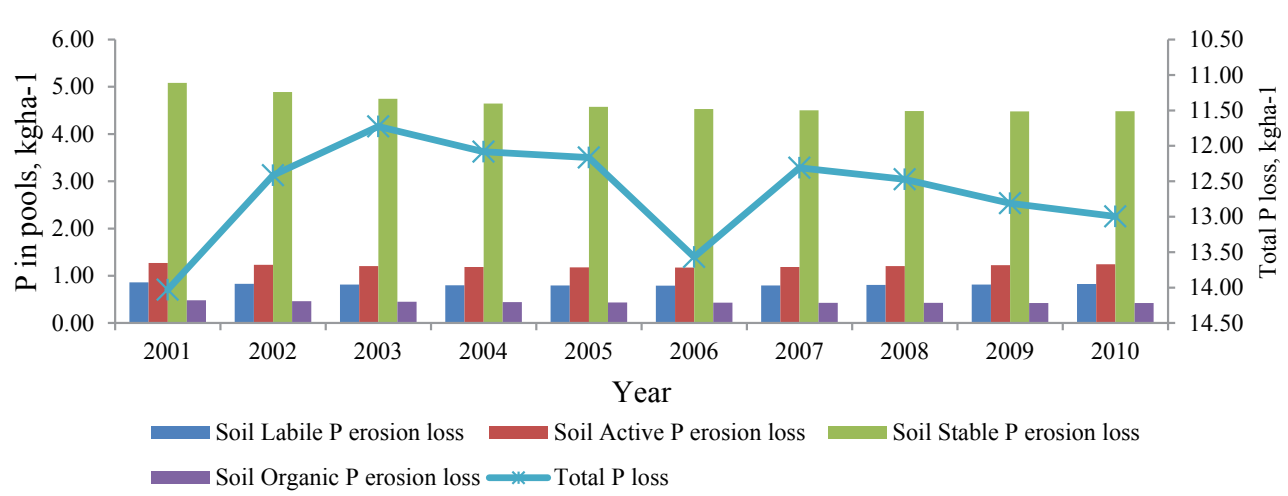

Figure 4: $\mathrm{P}$ pools versus total $\mathrm{P}$ loss.

phosphorus is lost from the nitisol based fields and $9.37 \pm 0.5 \mathrm{~kg} \mathrm{ha}^{-1}$ $\mathrm{yr}^{-1}$ phosphorus from vertisol lands which differ significantly $(\mathrm{p}$-value $=$ 0.0002). Accordingly, particulate $P$ loss from nitisol and vertisol is 7.1 $\pm 0.3 \mathrm{~kg} \mathrm{ha}^{-1}$ and $5.7 \pm 0.2 \mathrm{~kg} \mathrm{ha}^{-1}$ respectively (p-value $=0.0001$ ). This variation can be attributed to the high sorption tendency of the nitisol than the vertisol so that in the presence of runoff higher particulate $\mathrm{P}$ could be lost from nitisol fields. The higher clay content, aluminum and iron oxide in nitisol soils favor high adsorption of $\mathrm{P}$ ( $\mathrm{p}$-value $=$ $0.001)[10-12,18]$. In both soils, the P loss follows the dominant mode of sediment transport to the nearby receiving pools. Similar findings are reported in literatures [17,22,23]. Together with other hydrology and soil properties of the area, the movement of $\mathrm{P}$ is highly facilitated. For instance, the lower water permeability of the clay-dominated soils with the prevailing precipitation would ease $\mathrm{P}$ transport process via runoff. The APLE model that simulates the movement of $\mathrm{P}$ through surface runoff contains modules for sorption phenomenon based on the soil texture of the land considered. Consequently, the nitisols of the catchment should contribute a larger amount of $\mathrm{P}$ in comparison with the vertisol. Therefore, the nitisol soils with a higher sorption power were found to loss higher amount of particulate $\mathrm{P}$ that validates the logical output of the APLE model. However, to give the full picture of validation (both predictive and structural validity) of the model output, the P loss data are a mandatory, which is not available in the case of this study.

\section{Evaluation of factors for $P$ loss using best management practices (BMPs) principles}

Though $\mathrm{P}$ is essential nutrient for productive crop and livestock agriculture, its loss causes eutrophication of receiving surface waters. The best management practices (BMPs) to mitigate $\mathrm{P}$ export to surface water include soil and water conservation practices, other management techniques, and social actions appropriate for specific agronomic, environmental, and socioeconomic conditions. Source BMPs are designed to minimize $\mathrm{P}$ available to runoff, managing fertilizer to lower its soluble P content and reduce farm P imports. Transport BMPs are designed to limit runoff, erosion, and leaching as important pathways of P loss. These include such practices as conservation tillage, terracing, and stream buffers. Because source and transport BMPs do not address 


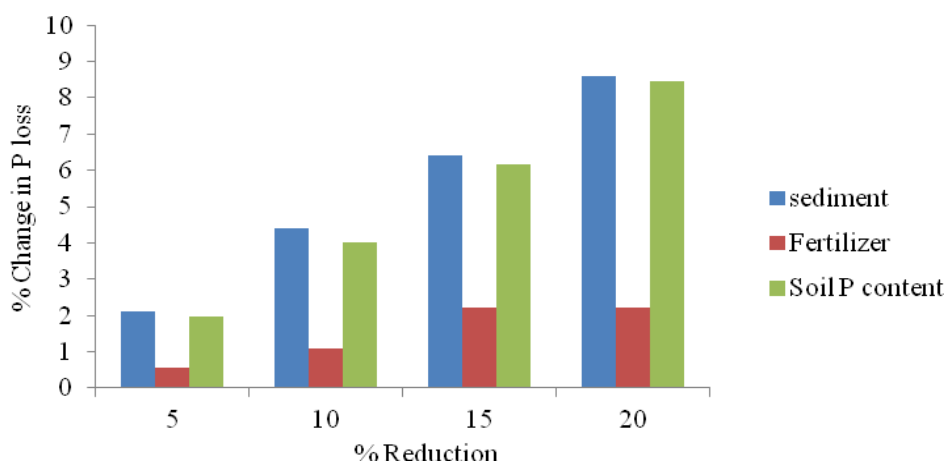

Figure 5: Change in $\mathrm{P}$ loss upon reduction of causing factors.

\begin{tabular}{|c|c|c|}
\hline Parameters & Uncertainties & Relative contribution \\
\hline Soil labile P & $5.7 \times 10^{-2} \mathrm{~kg} / \mathrm{ha}$ & 0.08 \\
\hline Annual runoff & $0.23 \mathrm{~kg} / \mathrm{ha}$ & 0.34 \\
\hline Eroded sediment & $0.21 \mathrm{~kg} / \mathrm{ha}$ & 0.31 \\
\hline Fertilizer P & $6.7 \times 10^{-2} \mathrm{~kg} / \mathrm{ha}$ & 0.09 \\
\hline RO/PT & $0.11 \mathrm{~kg} / \mathrm{ha}$ & 0.16 \\
\hline
\end{tabular}

Relative contribution of 1.00 is the sum of all the contributions by each parameter.

Table 6: Uncertainties of input parameters in prediction of $\mathrm{P}$ loss.

\begin{tabular}{|c|c|c|c|}
\hline Sampling dates & Phosphate, C(mg/L) & Discharge, $Q\left(\mathrm{~m}^{3} / \mathrm{s}\right)$ & Flux, $\left(\mathrm{mg} / \mathrm{l}^{*} \mathrm{~m}^{3} / \mathrm{s}\right)$ \\
\hline Mar/9/2008 & 0.021 & 3.98 & 0.084 \\
\hline Mar/22/2008 & 0.18 & 4.22 & 0.76 \\
\hline Oct/13/2008 & 0.09 & 31.45 & 2.83 \\
\hline Nov/6/2009 & 0.05 & 9.03 & 0.45 \\
\hline Nov/19/2009 & 0.03 & 11.41 & 0.32 \\
\hline Jun/5/2010 & 0.4 & 55.32 & 22.13 \\
\hline Jun/15/2010 & 0.06 & 62.15 & 3.98 \\
\hline Jun/21/2010 & 0.02 & 64.13 & 1.22 \\
\hline Jun/27/2010 & 0.02 & 72.31 & 1.45 \\
\hline Oct/4/2010 & 0.12 & 52.64 & 6.32 \\
\hline Oct/19/2010 & 0.08 & 24.35 & 1.95 \\
\hline Jul/6/2011 & 0.09 & 81.68 & 7.35 \\
\hline $\mathrm{Jul} / 22 / 2011$ & 0.09 & 142.34 & 12.81 \\
\hline Sep/11/2012 & 0.11 & 2.44 & 0.27 \\
\hline Dec/9/2012 & 0.07 & 5.55 & 0.39 \\
\hline Mar/12/2013 & 0.23 & 8.49 & 1.95 \\
\hline Aug/24/2013 & 0.55 & 184.22 & 101.32 \\
\hline Jan/8/2014 & 0.13 & 10.65 & 1.38 \\
\hline Jul/3/2014 & 0.34 & 180.12 & 61.24 \\
\hline
\end{tabular}

Table 7: Measured orthophosphate and discharge data from Gilgel gibe river downstream of Asendabo Bridge.

the main problem of farm and regional $P$ surpluses, long-term solutions must extend beyond the farm gate [24]. As indicated in figure 5, while reducing the sediment by $5 \%, 10 \%, 15 \%$ and $20 \%$, the simulated P loss reduction is $2.12 \%, 4.4 \%, 6.4 \%$ and $8.6 \%$ respectively. With similar percent reduction for fertilizer, a total $\mathrm{P}$ loss reduction ranges between 0.5 to $2.2 \%$. The other factor, which has great implication, i.e. soil $\mathrm{P}$ content was also reduced from $5 \%$ to $20 \%$ and the simulated P loss reduction ranges from two to 8.5 percent. This evaluation assumes two stages to be followed. First applying different BMPs techniques and analyze the observed change in each variable; second is evaluating the retained $\mathrm{P}$ that can be transferred from the land. Therefore, the values are computed after the first assumption is met. This implies that, the effort made to mitigate the $\mathrm{P}$ transfer into the nearby aquatic environment should give BMPs for sediment erosion and soluble $\mathrm{P}$ in the soil using standard practices such as conservation tillage, terracing, and stream buffers.

\section{Phosphorus load estimation in Gilgel gibe river}

To estimate phosphorus loading, it is necessary to sum the flux, which is expressed as mass per unit time, over the period of interest. Since the flux varies with time, this summing process can be expressed in integral form as shown in equation 3. Flux is often computed as the product of concentration and flow. Thus the three basic steps for estimating $\mathrm{P}$ load are: measuring water discharge, measuring $\mathrm{P}$ concentration, and calculating $\mathrm{P}$ loads (multiplying discharge times concentration over the time frame of interest).

The phosphorus load is the integral over time of the flux:

$$
\begin{array}{ll}
\text { Pload }=k \int^{t} \text { flux }(t) d t & \text { Equation } 3
\end{array}
$$

Where $f_{l u x}{ }^{t}(t)=\mathrm{C}(\mathrm{t})^{*} \mathrm{Q}(\mathrm{t})$, and $k=$ is a constant for converting units (34.7 used for ton/year), and $t$ is time.

As it is shown in table 7, there are $\mathrm{P}$ concentration and discharge data which gives the flux. Using equation 3 the $\mathrm{P}$ load is estimated from the beginning of the sampling date (March, 2008) until July 2014. The time interval between these periods is 77 months (6.4 years). Taking the average of both the concentration and discharge within the time interval ( $t_{1}=0$ to $t=6.4$ years), the average annual load is approximately 1660.6 ton. The cumulative load is determined by adding the calculated fluxes over all sampling intervals. Consequently, the cumulative load is nearly 7758.7 ton. Therefore, the Gilgel gibe reservoirs found to the downstream of the sampling station receive such an amount of $\mathrm{P}$ where the non-point source diffusion of $\mathrm{P}$ predominately contributes. The limitation to this approximation is the data inadequacy between the integral time intervals.

\section{Conclusion}

Gaining a detailed understanding of the operating processes in agricultural fields is important to explain how non-point sources of pollution affect the water quality of the aquatic environment. Phosphorus has been known to its potential damage to aquatic environment once found in excess. For decades there are several research conducted to study the transport and effect of $\mathrm{P}$ on the water bodies. However, still miles remain to develop efficient method that explicitly put the phosphorus fate. Therefore, studying the phosphorus transport has got an attention worldwide. In this study similar efforts were made to scrutinize the dominant 
transport mechanisms and amount transported through surface runoff. Accordingly, the result clearly indicated that, the main transport mechanism of $\mathrm{P}$ from the agricultural land is particulate mode of transport. However, a significant amount of $\mathrm{P}$ is also lost via dissolution. Consequently, the findings of this study conclude that the agricultural activities in conjunction with the rugged topography of the catchment rapidly affect the water quality of the reservoir. However, it found that applying the BMPs could also reduce substantial amount of $\mathrm{P}$ export. Particularly an effort made on sediment, soil $\mathrm{P}$ content and runoff generation reduction could bring positive impact to retain $\mathrm{P}$. In conclusion, the management practices designed to control the $\mathrm{P}$ transport should give emphasis to control erosion and available soil $\mathrm{P}$. The result of this finding also suggests that most tropical soils in Sub-Sahara countries may follow similar P loss pattern. Application timing and quantity of inorganic fertilizers could play a great role to achieve remarkable $\mathrm{P}$ transfer control using BMPs. Generally, attention should be given to the application of precision agriculture to avoid such problems.

\section{Acknowledgment}

We are highly thankful to Deutschen Akademischen Austauschdienst (DAAD) and Jimma University for financial support and Ethiopian National Metrology Agency. We would also thank Dr. Seid Tiku for the phosphorus concentration data.

\section{References}

1. Michael J, White a, Daniel E. Storm b, Philip R, et al (2010) A quantitative phosphorus loss assessment tool for agricultural fields. Environmental Modelling and Software. 25: 1121-1129.

2. Vadas PA, Owens LB, Sharpley AN (2008) An empirical model for dissolved phosphorus in runoff from surface-applied fertilizers. Agriculture, Ecosystems and Environment.

3. Zaimes GN, Schultz RC (2002) Phosphorus in Agricultural Watersheds. A Literature Review. 5-33.

4. Ambelu A, Koen Lock, Goethals PLM (2013) Hydrological and anthropogenic influence in the Gilgel Gibe I reservoir (Ethiopia) on macro invertebrate assemblages. Lake and Reservoir Management. 29: 143-150.

5. Radcliffe DE, Freer J and Schoumans O (2009) Diffuse Phosphorus Models in the United States and Europe: Their Usages, Scales, and Uncertainties. J Environ Qual 38: 1956-1967.

6. Vadas PA, Joern BC, Moore PA Jr (2012) Simulating Soil Phosphorus Dynamics for a Phosphorus Loss Quantification Tool. J Environ 41: 1750-1757.

7. Lemunyon JL, Gilbert RG (1993) The concept and need for a phosphorus assessment tool. Journal of Production Agriculture. 6: 483-486.

8. Veith T, Sharpley A, Weld J, Gburek W (2005) Comparison of measured and simulated phosphorus losses with indexed site vulnerability. Transactions of the ASAE. 48: 557-565.

9. [EELPA]-Ministry of Mines and Energy Ethiopian Electric Light and Power Authority (1997) Gilgel Gibe hydroelectric project. Environmental assessment main report. Ethiopia (Addis Ababa) 15-20.

10. Hadgu F, Gebrekidan H, Kibret K, Yitaferu B (2014) Study of phosphorus adsorption and its relationship with soil properties, analysed with Langmuir and Freundlich models. Agriculture, Forestry and Fisheries. 3: 40-51.

11. Behn C, Janssen M, Yalemsew GA, Lennartz B (2013) Phosphorus contents and phosphorous sorption in soils of the Gilgel Gibe catchment, SW Ethiopia. Geophysical Research Abstracts. 15: 8308.

12. Chimdi A, Gebrekidan H, Tadesse A, Kibret K (2013) Phosphorus Sorption Patterns of Soils from Different Land. American-Eurasian. Journal of Scientific Research 8: 109-116.

13. Vadas PA (2013) Annual Phosphorus Loss Estimator (1 ${ }^{\text {st }}$ edn.) Madison Wisconsin, USA: U.S. Dairy Forage Research Center.

14. US EPA]-US Environmental Protection Agency (1986) Quality Criteria for Water. EPA 440/5, 86-001. Washington (DC).

15. Devi R, Tesfahune E, Legesse W, Deboch B. (2008). Assessment of siltation and nutrient enrichment of Gilgel Gibe dam, Southwestern Ethiopia. Bioresour Technol. 99: 975-979.

16. Nebiyu A (2011) The Sustainable Use of Soil Resources of Gilgel Gibe Dam Catchment. Proceeding of the national workshop in integrated Watershed management on gibe-Omo Basin. Prepared by Jimma University and PHE Ethiopia Consortium. 39-42.

17. Eghball B, Gilley JE (2001) Phosphorus risk assessment index evaluation using runoff measurement. Journal of Soil and Water Conservation. 56: 202-206.

18. McDowell RW, Sharpley AN, Condron LM, Haygarth PM, Brookes PC (2001) Processes controlling soil phosphorus release to runoff and implications for agricultural management. Nutrient Cycling in Agro ecosystems. 59: 269-284.

19. DeLaune PB, Moore PA Jr (2001) Predicting Annual Phosphorus Losses from Fields Using the Phosphorus Index for Pastures. Better Crops. 85: 16-23.

20. Prairie YT, Kalff J (1986) Effect of catchment size on phosphorus export. Water Resour. Bull. 22: 465-470.

21. Bolster CH, Vedas PA (2013) Sensitivity and Uncertainty Analysis for the Annual Phosphorus Loss Estimator Model. J Environ Qual 42: 1109-1118.

22. David MB, Gentry LE (2000) Anthropogenic inputs of nitrogen and phosphorus and riverine export for Illinois, USA. J Environ Qual 29: 494-508.

23. Vaithiyanathan P, Correll DL (1992) The Rhode River Watershed: Phosphorus distribution and export in forest and agricultural soils. J Environ Qual 21: 280 288 .

24. Sharpley AN, Daniel T, Gibson G, Bundy L, Cabrera M, et al. (2006) Best Management Practices to Minimize Agricultural Phosphorus Impacts on Water Quality. U.S. Department of Agriculture, Agricultural Research Service, ARS 163: 50 